\title{
THE IMPACT
}

OF MONETARY

POLICY SHOCKS

ON COMMODITY

PRICES

by Alessio Anzuini, Marco J. Lombardi and Patrizio Pagano 


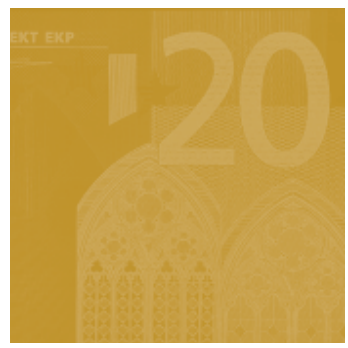

\title{
WORKING PAPER SERIES
}

NO I232 / AUGUST 2010

\section{THE IMPACT OF MONETARY POLICY SHOCKS ON COMMODITY PRICES '}

\author{
by Alessio Anzuini', Marco J. Lombardi, \\ and Patrizio Pagano ${ }^{4}$
}

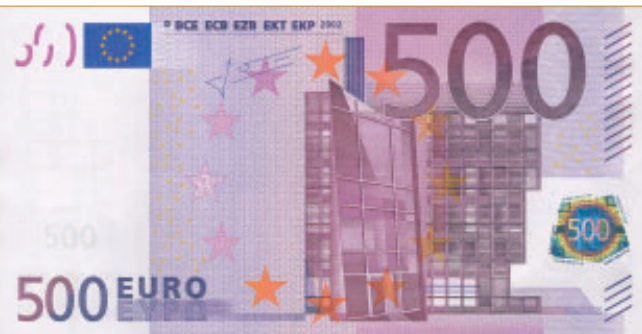

In 2010 all ECB publication feature a moti taken from the $€ 500$ banknote.
NOTE: This Working Paper should not be reported as representing the views of the European Central Bank (ECB).

The views expressed are those of the authors and do not necessarily reflect those of the $E C B$.

This paper can be downloaded without charge from http://www.ecb.europa.eu or from the Social Science Research Network electronic library at http://ssrn.com/abstract_id $=1650595$.

\footnotetext{
I Without implicating, we gratefully acknowledge useful comments received by Lutz Kilian, Ron Alquist and all seminar participants at the Bank of Canada. Views expressed in this paper are solely those of the authors and cannot be attributed to Banca d'Italia, the European Central Bank or the ESCB. 2 Corresponding author: Banca d'Italia and European Central Bank, Kaiserstrasse 29, D-603II Frankfurt am Main, Germany; e-mail: alessio.anzuini@ecb.europa.eu 3 European Central Bank, Kaiserstrasse 29, D-603II Frankfurt am Main, Germany; email: marco.lombardi@ecb.europa.eu 4 Banca d'Italia, Via Nazionale 9I, I-00/84 Rome, Italy; e-mail: patrizio.pagano@bancaditalia.it
} 
(c) European Central Bank, 2010

\section{Address}

Kaiserstrasse 29

60311 Frankfurt am Main, Germany

\section{Postal address}

Postfach 160319

60066 Frankfurt am Main, Germany

Telephone

+496913440

Internet

http://www.ecb.europa.eu

Fax

+496913446000

All rights reserved.

Any reproduction, publication and reprint in the form of a different publication, whether printed or produced electronically, in whole or in part, is permitted only with the explicit written authorisation of the ECB or the author(s).

Information on all of the papers published in the ECB Working Paper Series can be found on the ECB's website, http://www. ecb.europa.eu/pub/scientific/wps/date/ html/index.en.html

ISSN 1725-2806 (online) 


\section{CONTENTS}

Abstract

Non-technical summary

1 Introduction

2 Monetary shocks and commodity prices

2.1 Data and model details

2.2 The impact of a conventional monetary policy shock

2.3 The impact on individual commodity prices I3

2.4 Robustness

2.5 Monetary policy and commodity prices fluctuations

3 The transmission channel

3.1 Robustness check

4 Concluding remarks

Appendix

References 


\begin{abstract}
Global monetary conditions have often been cited as a driving factor of commodity prices. This paper investigates the empirical relationship between US monetary policy and commodity prices by means of a standard VAR system, commonly used in analysing the effects of monetary policy shocks. The results suggest that expansionary US monetary policy shocks drove up the broad commodity price index and all of its components. While these effects are significant, they however do not appear to be overwhelmingly large. This finding is also confirmed under different identification strategies for the monetary policy shock.
\end{abstract}

JEL Classification: E31, E40, C32.

Keywords: Monetary policy Shock, Oil Price, VAR. 


\section{Non-technical summary}

Commodity price developments have been one of the major sources of concern for policymakers during the recent years. A wide strand of literature has examined the impact of commodity prices on macroeconomic variables and the stance of monetary policy. Fewer attention has however been devoted to the other direction of causality, i.e. the impact of monetary conditions on oil and other commodity prices.

During the commodity price surge of 2008 some commentators indicated that loose monetary policy and persistently low interest rates could have at least in part fuelled the price hike (Hamilton, 2009). If this is so, it is then relevant to understand whether and to what extent the massive monetary policy easing which is nowadays taking place may sow the seeds for another surge in commodity prices. The aim of this paper is indeed to analyze to what extent an expansionary monetary policy shock may drive up commodity prices and through which channel.

Since the seminal contribution by Frankel (1984), monetary conditions and interest rates have attracted attention as possible driving factors of commodity prices. Most of the empirical literature devoted to the assessment of the relationship between monetary policy and commodity prices has focused on the US interest rate as an indicator of monetary policy stance (Frankel and Rose, 2009). However, interest rates may not fully represent the impact of a monetary policy shock and, more importantly, their movements can reflect the endogenous response of monetary policy to the general developments of the economy.

Our strategy is to identify a monetary policy shock in a VAR system for the US economy, and then assess its impact on commodity prices. This allows us not only to examine the impact of monetary policy net of other interaction channels, but also to avoid employing indicators of global monetary conditions which are inherently difficult to measure. Our main finding is that there is empirical evidence of a significant impact of monetary policy on commodity prices; in particular, an expansionary monetary policy shock drives up the broad commodity price index and all of its major components. This result is robust to the use of several different identification strategies of the monetary policy shock.

The variance decomposition suggests however that the impact of monetary policy on commodity prices is rather limited, though statistically significant. Still, we try to shed some light on the channel through which monetary policy shocks affect commodity prices, focusing on the case of oil. In particular, we investigate whether the positive impact on oil prices of a monetary policy loosening can be ascribed to incentives to stock accumulation, disincentives to immediate production or to financial flows. Results show that all these direct channels display the expected sign, but the bulk of the impact of monetary policy on commodity prices seems to transit through the indirect channel of expected growth and inflation, as also reported by Barsky and Kilian (2004).

Our findings also suggest that the extraordinarily monetary policy easing deployed to contrast 
the real effects of the financial crisis is likely to push commodity prices up, albeit to a small extent. However, we acknowledge that our identification scheme is not designed to account for unconventional monetary policy measures, so that larger effects cannot be ruled out. 


\section{Introduction}

Commodity price developments have been one of the major sources of concern for policymakers during the recent years. After having surged with increasing momentum to unprecedented levels in the course of 2008, prices of commodities fell abruptly in the wake of the financial crisis and the global economic downturn. Since the beginning of 2009, however, commodity prices first stabilised, and then resumed an upward path, characterized by relatively high volatility. As commodity prices in general - and the oil price in particular - are an important component of Consumer Price Indexes, the evolution of these prices and the driving forces behind them are clearly crucial for the conduct of monetary policy (Svensson, 2005).

A wide strand of literature has examined the impact of commodity prices - oil in particular - on macroeconomic variables (see e.g. Kilian, 2008, for a survey), but fewer attention has been devoted to the other direction of causality, i.e. the impact of monetary conditions on oil and other commodity prices. In this paper we focus on the latter, to analyze to what extent an expansionary monetary policy shock may drive up commodity prices and through which channel.

While supply and demand factors can in general explain the bulk of the fluctuations in commodity prices, other forces may at times play a role (Hamilton, 2009). Kilian (2009) and Alquist and Kilian (2010) highlight the relevance of precautionary demand shocks, which increase current demand for oil due to an increase in uncertainty about future oil supply shortfalls, in the behaviour of oil prices. ${ }^{1}$ Since the seminal contribution by Frankel (1984), monetary conditions and interest rates have attracted attention as possible driving factors of commodity prices. Frankel (1986) extends Dornbusch's theory of exchange rate overshooting to the case of commodities and, using no-arbitrage conditions, derives a theoretical link between oil prices and interest rates. Barsky and Kilian $(2002,2004)$ show that monetary policy stance is a good predictor of commodity prices. In particular, Barsky and Kilian (2002) also suggest that the oil price increases of the 1970s could have been caused, at least in part, by monetary conditions. ${ }^{2}$

Most of the empirical literature devoted to the assessment of the relationship between monetary policy and commodity prices has focused on the US interest rate as an indicator of monetary policy stance (Frankel, 2007, Frankel and Rose, 2009). However, interest rates may not fully represent the impact of a monetary policy shock and, more importantly, their movements can reflect the endogenous response of monetary policy to the general developments of the economy. For instance, Bernanke, Gertler and Watson (1997), using a VAR framework, suggest that positive shocks to the oil price induce a monetary policy response which can amplify the contractionary effects of the oil

\footnotetext{
${ }^{1}$ Anzuini, Pagano and Pisani (2007) show that such oil shocks contributed significantly to the US recessions in the last thirty years.

${ }^{2}$ Nakov and Pescatori (2010) argue, in line with Kilian (2009), that oil prices should be treated endogenously also in DSGE models. In such a framework, Gillman and Nakov (2008) find that nominal oil prices reacts proportionally to nominal interest rates shocks
} 
price shock itself; Kilian and Lewis (2009), however, report no evidence of systematic Fed reaction to oil shocks after 1987.

During the commodity price surge of 2008 some commentators indicated that loose monetary policy and persistently low interest rates could have at least in part fuelled the price hike (Hamilton, 2009). If this is so, it is then relevant to understand whether and to what extent the massive monetary policy easing which is nowadays taking place may sow the seeds for another surge in commodity prices. In this paper, we will not work with a plain analysis of comovements between commodity prices and interest rates, but rather identify a monetary policy shock in a VAR system for the US economy, and then assess its impact on commodity prices. This allows us not only to examine the impact of monetary policy net of other interaction channels, but also to avoid employing indicators of global monetary conditions which are inherently difficult to measure. More specifically, we will use a standard identification scheme for the monetary policy shock (Kim, 1999) and we will then project each of the commodity prices on this shock in order to single out the responses of the different prices to the same monetary policy shock. We find empirical evidence of a significant impact of monetary policy on commodity prices; in particular, an expansionary monetary policy shock drives up the broad commodity price index and all of its major components. Although the methodology is very different, our approach is similar in spirit to that of Frankel and Hardouvelis (1985), which investigated the impact of money supply announcements on commodity prices; the main methodological difference lies in the fact that in our case we work with an identified monetary policy shock in a VAR system.

In addition, we assess the robustness of the results by repeating the exercise using several different identification strategies of the monetary policy shock, which are commonly used in the literature. In particular, remaining in a VAR context, we used also the Choleski identification strategy proposed by Boivin and Giannoni (2006) and that based on sign restrictions in the spirit of Uhlig (2005) and Canova and De Nicolò (2002). The actual implementation of the sign restrictions is obtained through the algorithm developed in Rubio-Ramírez et al. (2010). We also analysed the effect on commodity prices of the monetary policy shocks identified according to Kuttner (2001) and Romer and Romer (2004). Overall, all these different strategies lead to similar conclusions.

The variance decomposition suggests that the impact of monetary policy on commodity prices is rather limited, though statistically significant. Still, we try to shed some light on the channel through which monetary policy shocks affect commodity prices, focusing on the case of oil. In particular, we investigate whether the positive impact on oil prices of a monetary policy loosening can be ascribed to incentives to stock accumulation, disincentives to immediate production or to financial flows. Results show that all these direct channels display the expected sign, but the bulk of the impact of monetary policy on commodity prices seems to transit through the indirect channel of expected growth and inflation, as also reported by Barsky and Kilian (2004).

The plan of the paper is the following. In section 2 we evaluate the impact of monetary policy shocks on the commodity price index and on its major components. In particular, we first describe 
the theoretical arguments according to which commodity prices should react to monetary policy shocks. Next, we present the data and the econometric framework, which includes the identification scheme, and then we provide VAR evidence and robustness analysis. In section 3 we evaluate the trasmission channels through which monetary policy may affect commodity prices. The last section contains some concluding remarks.

\section{Monetary shocks and commodity prices}

The impact of monetary policy on commodity prices has been studied by Barsky and Kilian (2002, 2004), who argue that the channel through which monetary policy exerts its impact on commodity prices is via (expectations of) stronger inflation and economic growth. There are however a number of other channels, related to the opportunity cost of investing in real assets, according to which an expansionary monetary policy can cause an increase in commodity prices. Frankel (2007) summarizes them as: i) low interest rates tend to reduce the opportunity cost of carrying inventories, increasing their demand for commodities; ii) on the supply side, lower rates create an incentive not to extract today exhaustible commodities, as the cost of holding inventories 'in the ground' also decreases; iii) for a given expected price path, a decrease in interest rates reduces the carrying cost of speculative positions, making it easier to bet on assets such as commodities; under certain conditions, this will put upward pressure on futures price and, by arbitrage, also on spot prices.

To gauge the quantitative effect of monetary policy shocks on commodity prices, we estimate a VAR for the US, the largest oil-consuming economy in the world.

\subsection{Data and model details}

Our dataset consists of monthly variables from January 1970 to September 2009. ${ }^{3}$ The variables are: the federal funds rate, the money stock (M2), the consumer price index, the industrial production index and a commodity price index (in dollars). After identifying the monetary policy shock we add, ordered as last, the commodity price sub-category for which we are interested in recovering the response. ${ }^{4}$ We have considered several commodities, one at a time, but for reasons of space we only report results for four commodity prices: a broad index, two sub-indices (metals and foodstuffs) and crude oil.

We estimate a VAR system with $p=12$ lags including the Federal fund rate, industrial

\footnotetext{
${ }^{3}$ Admittedly, this covers a very long time span during which policy shifts may have happened, as also documented by Barsky and Kilian (2004). For robustness check, we also estimated the model on a restricted, post-Volcker sample starting in January 1980. Results, available upon request, display however no significant differences.

${ }^{4}$ In practice, we assume that all variables have a contemporaneous effect on the price of the commodity for which we want to recover the response, but this last variable does not affect contemporaneously all the others.
} 
production, M2, consumer price index and the commodity price index. All variables except the Fed fund rate are in log-level and are stored in the vector $y_{t}$.

The structural form is therefore:

$$
C(L) y_{t}=\eta_{t}
$$

where $C(L)$ is a polynomial matrix in the lag operator and $V C V\left(\eta_{t}\right)=\Lambda$ is a diagonal matrix with the variances of the structural shocks as elements. We estimate (ignoring predetermined variables) the reduced form:

$$
y_{t}=A(L) y_{t-1}+\varepsilon_{t}
$$

where $A(L)$ is a polynomial matrix in the lag operator and $V C V\left(\varepsilon_{t}\right)=\Sigma$ and $\eta_{t}=C_{0} \varepsilon_{t}$ and therefore $\Sigma=C_{0}^{-1} \Lambda C_{0}^{-1 \prime}$.

In order to obtain a just identified system we need $\frac{n(n-1)}{2}$ restrictions. Our baseline identification scheme to identify a US monetary policy shocks is the same as in Kim (1999):

$$
\left[\begin{array}{c}
\eta_{t}^{m s} \\
\eta_{t}^{m d} \\
\eta_{t}^{c p i} \\
\eta_{t}^{i p} \\
\eta_{t}^{c o m}
\end{array}\right]=\left[\begin{array}{ccccc}
1 & g_{12} & 0 & 0 & g_{15} \\
g_{21} & 1 & g_{23} & g_{24} & 0 \\
0 & 0 & 1 & g_{34} & 0 \\
0 & 0 & 0 & 1 & 0 \\
g_{51} & g_{52} & g_{53} & g_{54} & 1
\end{array}\right]\left[\begin{array}{c}
\varepsilon_{t}^{m s} \\
\varepsilon_{t}^{m d} \\
\varepsilon_{t}^{c p i} \\
\varepsilon_{t}^{i p} \\
\varepsilon_{t}^{c o m}
\end{array}\right]
$$

where the $\eta \mathrm{s}$ denote the structural disturbances while the $\varepsilon \mathrm{s}$ are the residuals in the reduced form equations, which represent by construction unexpected movements (given the information in the system) of each variable. All restrictions are zero (exclusion) restrictions.

The first line of the VAR system, where the interest rate appears on the left hand side, is a money supply equation modelled as a reaction function of the monetary authority; irrespective of the identification scheme used this interpretation is standard in this literature. Here the assumptions are that, due to an informational delay, the current level of prices and industrial production are not available to the monetary authorities.

The second line is a standard money demand equation. The demand for real money balances depends on real activity and the opportunity cost of holding money - the nominal interest rate. The third and fourth lines encapsulate the hypothesis of price stickiness or adjustment costs: real activity responds to price and financial signals only with a lag. The interest rate, money, and the commodity price index are assumed not to affect real activity contemporaneously. The last equation is an arbitrage equation which describes equilibrium in the commodity market as a kind of financial market equilibrium. All variables are assumed to have contemporaneous effects on the commodity price. 
Based on Akaike information criteria we select $12 \operatorname{lags}^{5}$; with monthly data our lags structure capture one year of dynamics, which appears to be sufficient to eliminate residuals autocorrelation.

After identifying the shock we re-estimate the system adding the oil price or the single commodity price for which we want to trace the response, and the scheme becomes the following:

$$
\left[\begin{array}{c}
\eta_{t}^{m s} \\
\eta_{t}^{m d} \\
\eta_{t}^{c p i} \\
\eta_{t}^{i p} \\
\eta_{t}^{c o m} \\
\eta_{t}^{\text {oil }}
\end{array}\right]=\left[\begin{array}{cccccc}
1 & g_{12} & 0 & 0 & g_{15} & 0 \\
g_{21} & 1 & g_{23} & g_{24} & 0 & 0 \\
0 & 0 & 1 & g_{34} & 0 & 0 \\
0 & 0 & 0 & 1 & 0 & 0 \\
g_{51} & g_{52} & g_{53} & g_{54} & 1 & 0 \\
g_{61} & g_{62} & g_{63} & g_{64} & g_{65} & 1
\end{array}\right]\left[\begin{array}{c}
\varepsilon_{t}^{m s} \\
\varepsilon_{t}^{m d} \\
\varepsilon_{t}^{c p i} \\
\varepsilon_{t}^{i p} \\
\varepsilon_{t}^{c o m} \\
\varepsilon_{t}^{o i l}
\end{array}\right]
$$

In ordering the new price as last we allow for a contemporaneous effect of all other variables on this price while assuming that any shock to the last variable will affect all other variables with a one month delay. ${ }^{6}$ Kilian and Vega (2008), however, report no evidence of any contemporary and systematic reaction of oil prices to macroeconomic announcements; based on this result, we conducted some robustness analysis testing some over-identifying restrictions, in particular: we estimated a system where $g_{62}=g_{63}=g_{64}=0$, and results were virtually unchanged. We then excluded commodity price from the Fed reaction function $\left(g_{15}=0\right)$ and again results did not change. ${ }^{7}$

\subsection{The impact of a conventional monetary policy shock}

As said, the US monetary policy shock is identified in a five variables VAR system. We here focus on the response of the commodity price index, which is the variable ordered as last, to the monetary policy shock, defined as a 100 basis point reduction in the Federal funds rate equation (Figure 1).

All responses have the expected sign. Only the response of the CPI is not significant, although the sign is as expected. Focusing on the response of the commodity price index to the monetary shock, it peaks rather quickly at $5.6 \%$ after just three months, then the effect slowly declines. The response appears to be significant and persistent, as it takes three years for it to converge back to the baseline. The magnitude of the effect, however, is somehow limited given that the monetary policy shock leads to an increase of the commodity price index of roughly $3 \%$, in the first two years

\footnotetext{
${ }^{5}$ We however checked that results remained unchanged using 10 up to 14 lags.

${ }^{6}$ Pagano and Pisani (2009) document that taking into account business cycle indicators may help in forecasting oil prices.

${ }^{7}$ Note that in our identification scheme the Federal Reserve never responds to the development in price of a single commodity. Moreover, it is worth to remembering that in general a non-zero coefficient in the impact matrix means that variables may respond contemporaneously to shocks, not that they necessarily do.
} 
Figure 1: Impulse response functions to a 100 basis points monetary policy easing
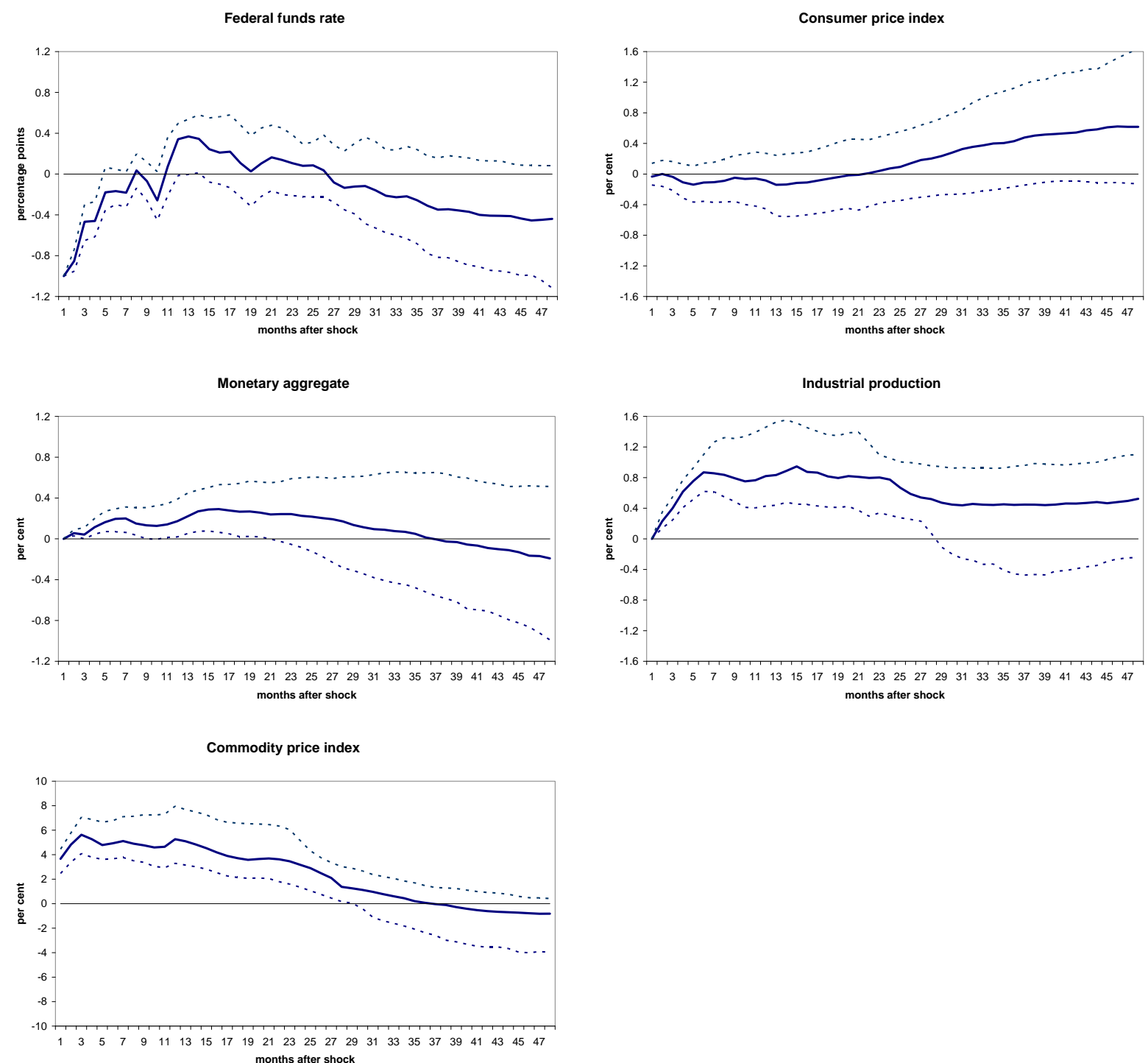

Notes: the x-axes reports the months after the shock. Dashed lines are $68 \%$ confidence bands.

after the shock. ${ }^{8}$ As the effect on commodity prices is positive and significant on impact and the CPI responds only sluggishly, there is a significant effect of monetary policy on relative prices. This effect is however reabsorbed in the medium run, when CPI starts to increase and commodity prices converge back to lower levels. The hump-shaped response of commodity prices testifies an initial overshooting - which dies out after few quarters - with respect to their long run level. This effect is usually (see e.g. Furlong and Ingenito, 1996) ascribed to the higher flexibility of the commodity prices with respect to the price of other items. This interpretation may suggest that part of the increase in commodity prices is due to the increase in the short term inflation expectation following a monetary expansion.

\footnotetext{
${ }^{8}$ Note that our monetary policy shock has been normalised to 100 basis points, which is quite larger than the usual one standard deviation shock used in the literature.
} 


\subsection{The impact on individual commodity prices}

After having identified the monetary policy shock, we add to the system the commodity price for which we want to trace the response. ${ }^{9}$ For all the commodities considered a monetary expansion generates an increase in price, yet the size and the time path of such increase vary considerably (Figure 2).

The impact on oil is rather sharp, peaking six months after the shock, but then vanishes after ten months. The response of metals is rather similar, although it has a second (significant) peak eighteen months after the shock. Food commodities instead respond in a rather smooth and persistent fashion, as the effects remain significant up to three years after the shock has occurred.

\subsection{Robustness}

Results presented above rest upon the identifying assumptions of the monetary policy shock. Admittedly, the scheme we have employed (Kim, 1999) is not the only possible, and we chose it on the grounds of its close connection with our setup, as well as of its simplicity and widespread use in the literature. In this section we examine to what extent our results remain valid when using different identification schemes for the monetary policy shock. The literature on monetary policy shocks is vast and we do not aim at being exhaustive. Rather, we will concentrate on four schemes that are somehow stemming from different approaches to the issue, and that are very popular in the applied literature.

The first alternative shock we will consider is due to Boivin and Giannoni (2006), and is based on a simple VAR with Choleski identification featuring (in order) output, inflation, commodity prices and the Federal funds rate. ${ }^{10}$ This approach has become very popular in the recent years, due to its simplicity.

The second alternative identification scheme is based on sign restrictions. Following, Faust (1998), Canova and De Nicolò (2002), and Uhlig (2005) we impose sign restrictions directly on impulse responses, i.e., after an expansionary monetary policy shock, the interest rate falls while money, output, and prices rise. As we focus on the response of the commodity prices no restriction is imposed on this variable. The response of the single subcomponent of the commodity price index is then obtained (as before) by simply adding the new variable to the old system without any further restriction. The actual implementation of this scheme is obtained through a $Q R$ decomposition following Rubio-Ramirez et al. (2010). We will use this identification strategy only to assess the robustness of the response of commodity prices (and subcomponents) to a monetary policy shock.

\footnotetext{
${ }^{9}$ This procedure is often referred to as "marginal method" and has been proposed by Kim (2001).

${ }^{10}$ Boivin and Giannoni (2006) employ (quarterly) GDP as a measure of output; given our monthly setup, we had to replace this with Industrial Production. This however seems not to affect the validity of the identification scheme.
} 
Figure 2: Response of individual commodities to a 100 basis points monetary policy easing Oil

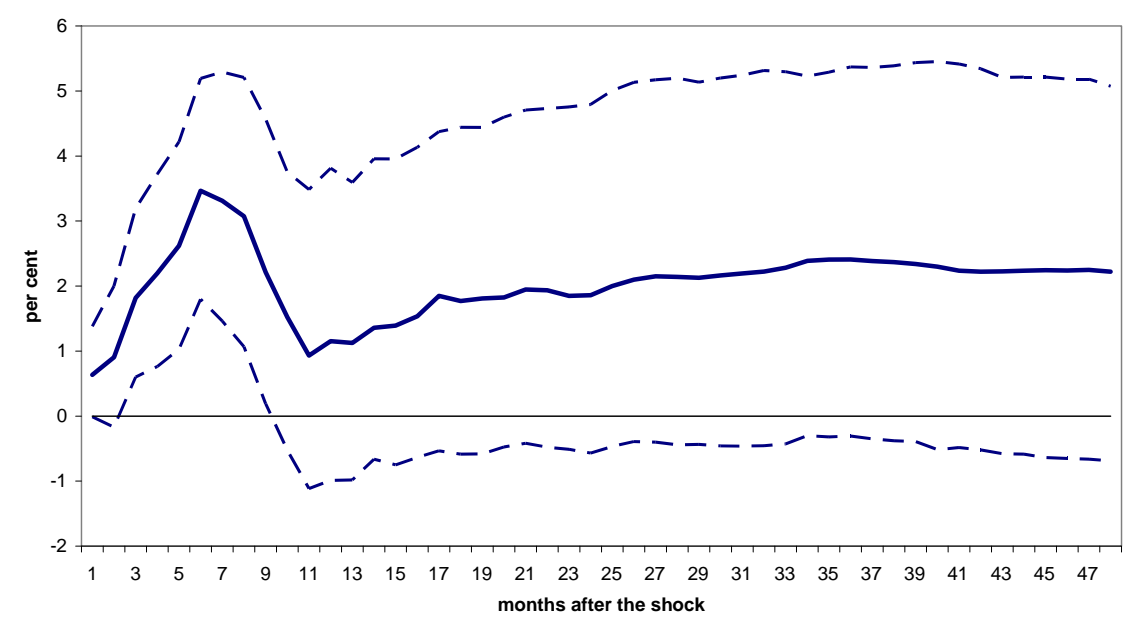

Metals

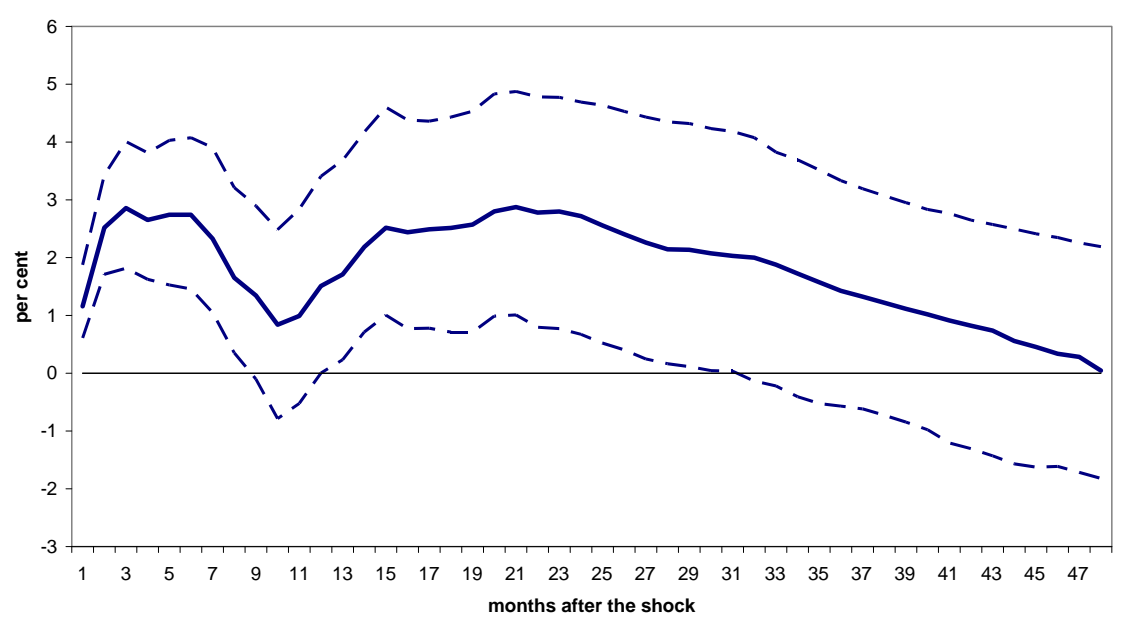

Food

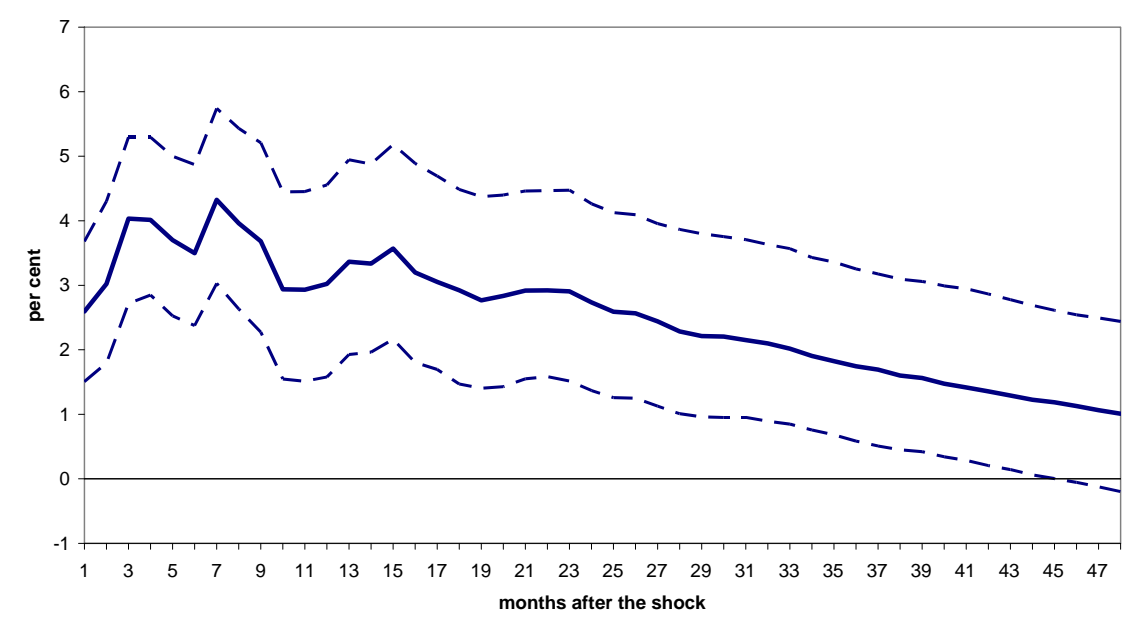

Notes: Dashed lines are $68 \%$ confidence bands. 
In fact, sign restrictions have been the subject of some criticism, given that all percentiles of the distribution in this case are computed across different rotations, which correspond to different models (Fry and Pagan, 2007). As a consequence, we see little value in extracting a monetary policy shock by selecting an arbitrary rotation, or averaging across shocks generated by different rotations, and we will not use it in the robustness analysis of the transmission channel of the next section.

We then move to other identification schemes not based on a VAR: our third alternative relies instead on financial markets information. Kuttner (2001) proposes to gauge a monetary policy shocks by subtracting from the actual change in the federal funds rate its expectation, i.e. compute the difference between Federal funds futures immediately before and after the decision of the FOMC. The idea is that many of the monetary policy decisions (and often the size of the change) are expected and therefore cannot be labelled as "shocks". The remaining monetary policy 'surprises' that agents face should hence produce stronger effects. Such series of monetary policy shocks is available since 1989, when the futures market for the Fed funds rate was established at the Chicago Board of Trade. To determine how commodity prices respond to monetary shocks we simply regress the log change in the commodity price index on a constant, its own lagged values, and lagged values of the policy measure. The lagged values of the shock series are included to capture the direct impact of shocks on commodity price change, and the lagged values of commodity price changes are included to control for the normal dynamics of the commodity price index. ${ }^{11}$

The last alternative monetary policy shock series we will consider is that derived by Romer and Romer (2004). Such scheme combines narrative accounts of each FOMC meeting included in the minutes with the Federal Reserve's internal forecasts of inflation and real activity (the "Greenbook" forecasts) to purge the intended funds rate of monetary policy actions taken in response to information about future economic developments. The resulting series of monetary shocks should show changes in the funds rate not taken in response to information about future economic developments. Unfortunately the series is not very up-to-date as it is available only from January 1969 to December $1996 .{ }^{12}$

In Figure 3, we plot - besides the impulse response function derived with our baseline identification scheme (Kim, 1999) and its 68\% confidence bands - the impulse responses obtained under the alternative identification strategies. All the different methodologies display an increase in commodity prices in the first few months after the shock has occurred. ${ }^{13}$ The response obtained

\footnotetext{
${ }^{11}$ We included 18 lags of (log) commodity price changes and 4 lags of the monetary policy measure, plus a complete set of monthly dummies.

${ }^{12}$ In the regression with such shock we include 18 lags of log commodity price change and 6 lags of the monetary policy measure, plus a complete set of monthly dummies.

${ }^{13} \mathrm{It}$ is worth noticing that this result appears also in other VAR studies on the effects of monetary policy shocks. For instance, Christiano, Eichenbaum and Evans (1999), in a recursive VAR featuring (in order) industrial production, CPI, an index of commodity prices, the Fed funds rate, nonborrowed reserves and total reserves, find that a standard deviation increase in the Fed funds delivers a significant and persistent fall in the commodity price index. Faust,
} 
with the monetary shock à la Kuttner (2001) is the most similar on impact, but it is also rather shortlived. The other responses are less pronounced, but considerably more persistent. Overall, they support the above conclusion that commodity prices increase after an expansionary monetary policy shock, but that the size of such effect is limited. ${ }^{14}$

Figure 3: Response of the commodity price index to a -100bp monetary shock

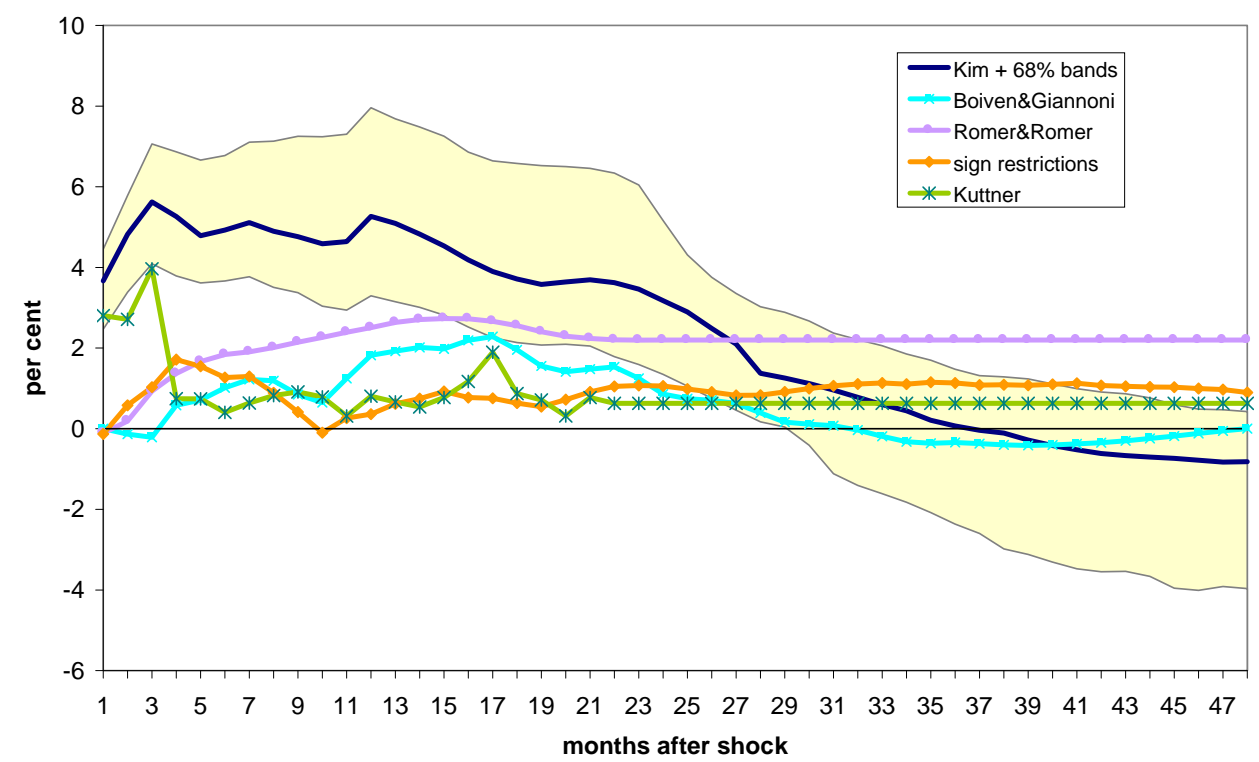

Similar results are obtained for the responses of the individual commodities analyzed before (see Figure 4). In particular, error bands (not reported) always overlap those obtained with the identification by Kim (1999). As for the commodity price index, the responses obtained with the approach à la Boivin and Giannoni (2006) are very similar to those obtained with the baseline identification. Also the response obtained using the monetary shocks calculated by Romer and Romer (2004) are remarkably close to the baseline median response, especially in the case of oil and metals.

\subsection{Monetary policy and commodity prices fluctuations}

Given the significant effect of monetary shocks, one may wonder how large is their relative contribution to overall commodity price fluctuations. This question may be tackled by means of a

Swanson and Wright (2004) find a similar result in a VAR featuring the same variables, but having identified the monetary shock with high-frequency financial merkets data.

\footnotetext{
${ }^{14}$ The confidence bands for the response of all variables included in the two VARs discussed here are reported in
} appendix, alongside the confidence bands for the response of all variables derived under the baseline method. 
Figure 4: Response of individual commodities to a 100 basis points monetary policy easing

Oil

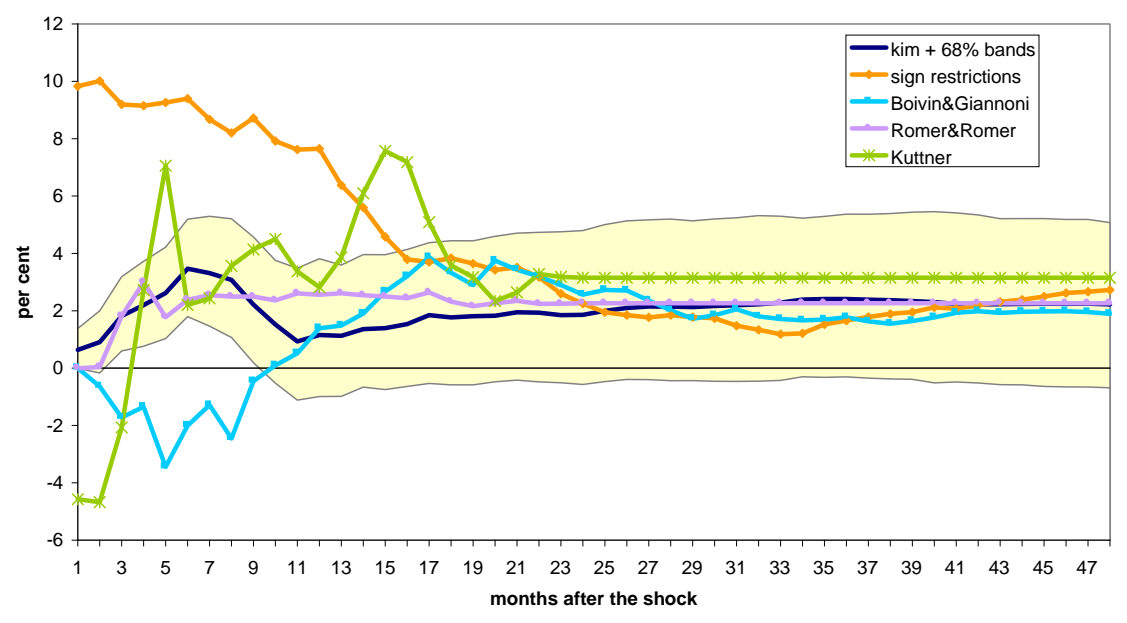

Metals

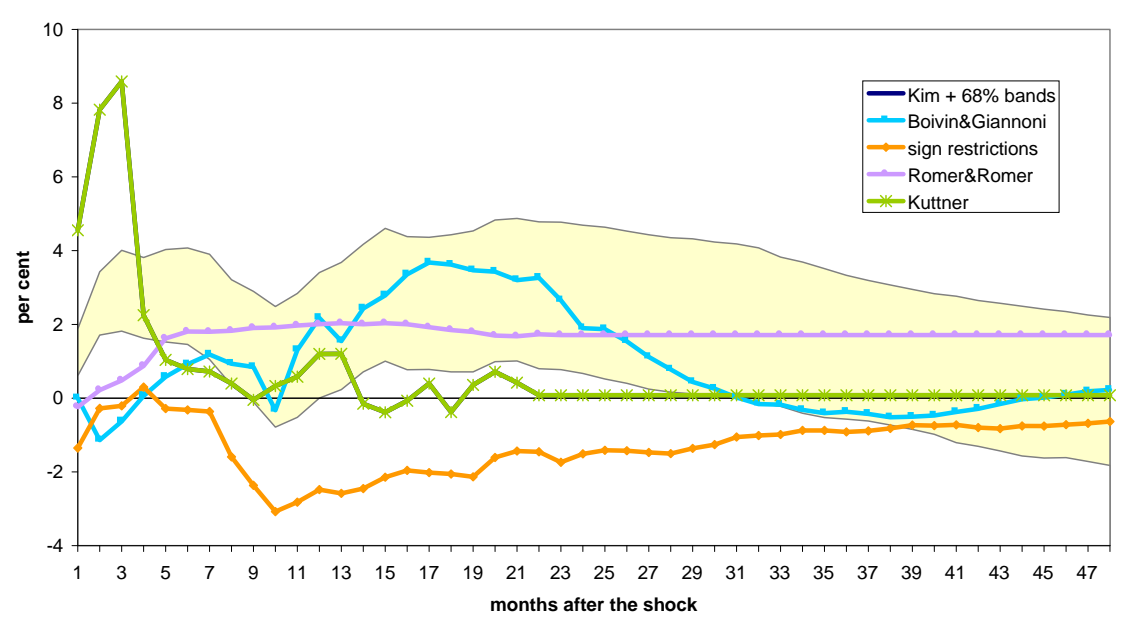

Food

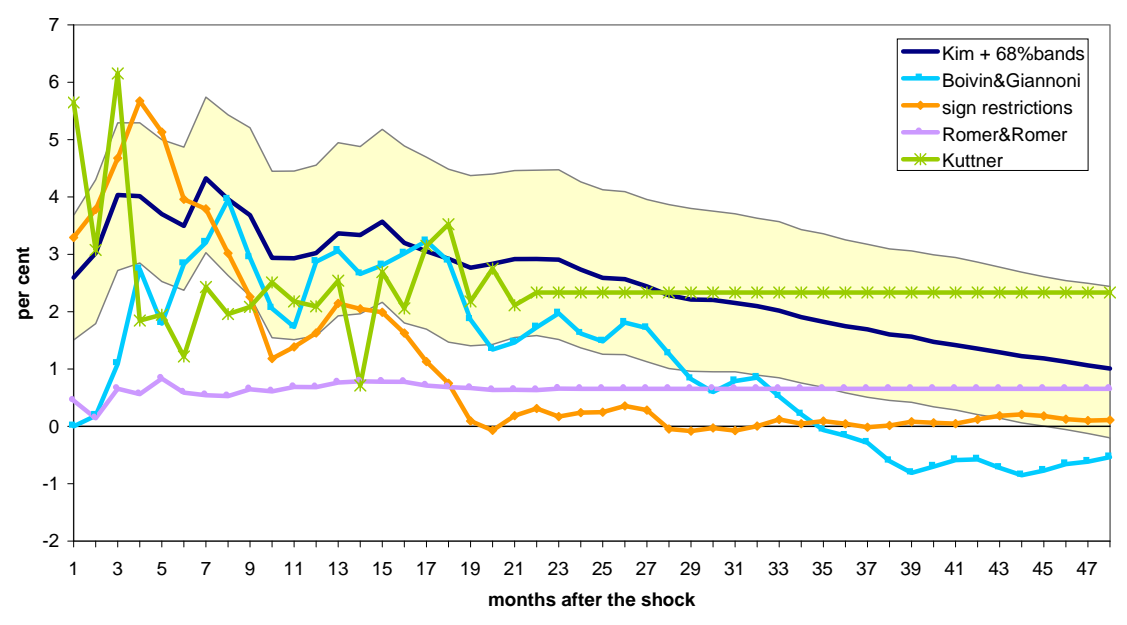


forecast error variance decomposition, which measures the percentage share of the forecast error variance due to a specific shock at a specific time horizon.

In Figure 5 we report the forecast error variance decomposition of the commodity price index and individual commodities with respect to the monetary shocks. The horizons at which forecast errors are calculated are indicated on the x-axis. The median percentage of the variance of the commodity index hovers around 15 percent, whereas contributions to oil and metals prices are, respectively, around 4 and 8 percent. Food commodities seem to have responded more to monetary policy shocks, which post a variance contribution of around 20 percent.

Figure 5: Forecast error variance decomposition

Commodity price index

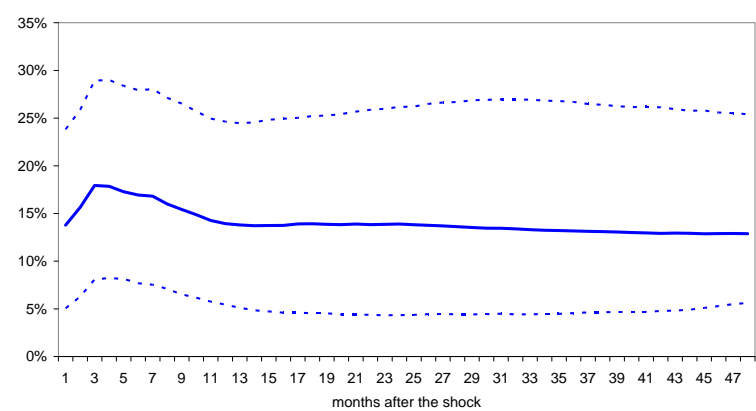

Metals

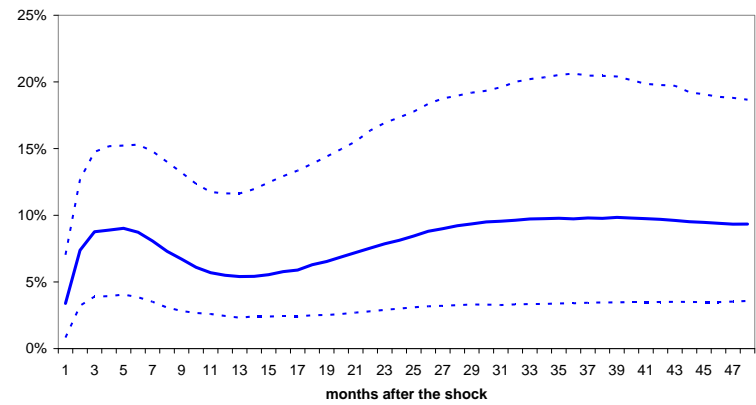

Oil

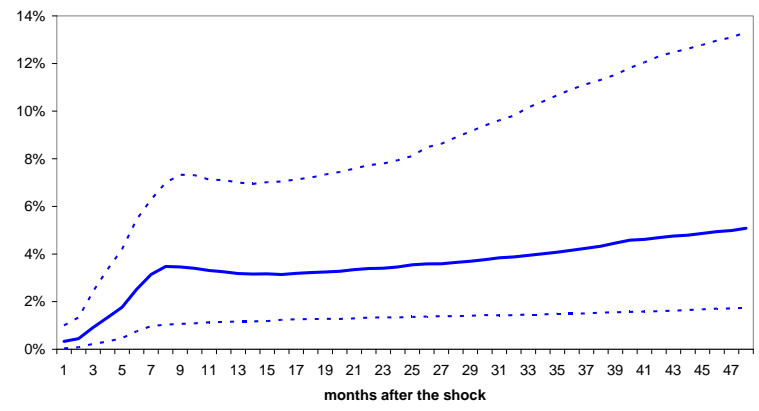

Food

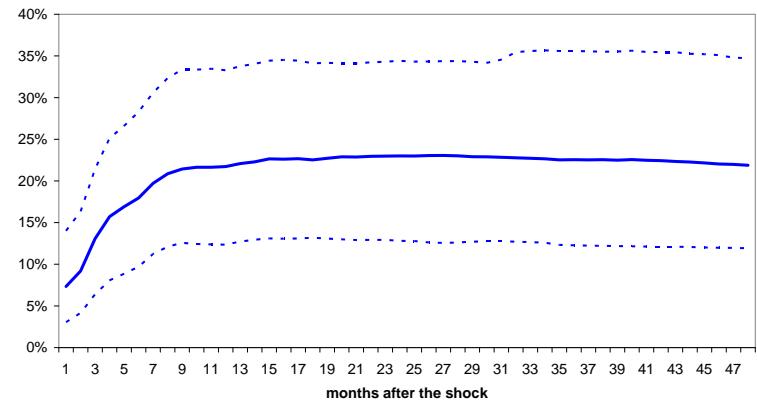

Notes: Dashed lines are $68 \%$ confidence bands.

Overall, we may conclude that monetary policy shocks help predicting commodity price movements but these shocks are not the main sources of fluctuations in prices. This result is in line with that of Barsky and Kilian (2002), Frankel (2007) and Frankel and Rose (2009), who find, at best, mixed evidence on the impact of interest rates on commodity prices.

\section{The transmission channel}

Having found a significant impact of the monetary policy shocks on commodity prices, however, does not tell us anything about the channel through which the effect is taking place. As anticipated, besides the indirect impact through expectations of inflation and growth, there are other 
direct channels through which monetary policy can exert its impact on commodity prices. More specifically, we have mentioned an 'inventory channel', a 'supply channel' and a 'financial channel' (Frankel, 2007).

We will here try to assess the relevance of such alternative channels for the case of oil. The reason of the choice is twofold: on one hand, oil is by far the most relevant commodity for the global economy, and its macroeconomic impacts have been studied extensively, on the other hand, comprehensive data is available on inventories and production, which is not the case for other commodities.

To make such assessment, we will first check whether the monetary policy shock à la Kim (1999) is able to explain fluctuations in oil inventories and oil supply, and speculative activity in futures markets. The data on oil inventories refers to US industry stocks of crude oil, collected by the US Energy Information Administration, and covers the time span from January 1970 until September 2009. The data on oil supply refers to world production of crude oil, as measured by the International Energy agency, and is from February 1984 to September 2009. Measuring speculative activity in crude oil futures market is a more daunting task. The US Commission for Futures Trading in Commodities (CFTC) collects and disseminates weekly data on the positions held by non-commercial agents in WTI crude oil futures contracts traded on the NYMEX; data is available since January 1996. A measure of speculative activity widely employed in the literature is the so-called non-commercial net long positions, i.e. the difference between the number of long and short positions held by agents not related to physical oil. ${ }^{15}$ The rationale is that a positive net positioning should suggest that non-commercial agents, i.e. speculators, are mostly bullish about oil price prospects.

In practical terms, we will regress net long positions in futures and changes in oil supply and oil stocks on their lags and on the monetary policy shock. ${ }^{16}$ Results, reported in Table 1, highlight that all variables are somehow sensible to the monetary policy shock. Furthermore, the signs of the coefficients are in accordance with the theory: a positive shock (i.e. a tightening of the monetary policy stance) produces an increase in oil production (as producers find more convenient to extract oil today and invest their revenues at higher rates), a decrease in oil inventories (as the opportunity cost of holding inventories becomes higher), and a decrease in speculative positions (as investors face a higher opportunity cost). It is also interesting to point that lagged values of the monetary

\footnotetext{
${ }^{15}$ There are a number of caveats related to measuring speculative activity with such an indicator. First of all, the distinction between commercial and non-commercial agents is somehow arbitrary, and does not imply that only noncommercials can act as speculators: for example, shouldn't an airline betting on oil price increases also be labelled as speculator? And why should a pension fund taking a long position in energy futures to diversify its portfolio and hedge against inflation be labelled as speculator? Second, index funds, i.e. financial instruments that replicate oil price developments, are managed by swap dealers and are hence fall in the commercial category. Finally, data is incomplete as it covers only regulated markets.

${ }^{16}$ The series of oil stocks and, to a lesser extent, oil production present a marked pattern of seasonality, which was removed by simply regressing on seasonal dummies.
} 
Table 1: Regression results of oil supply, oil stocks on the monetary policy shock

\begin{tabular}{ccccc}
\hline \hline Dep. Variable: & Supply & & & $R^{2}=0.0129$ \\
Variable & Coefficient & Std. error & t-stat & P-value \\
MP Shock & 0.4021 & 0.2128 & 1.8897 & 0.0597 \\
Supply (-1) & 0.0432 & 0.0570 & 0.7588 & 0.4485 \\
\hline Dep. Variable: & Stocks & & & $R^{2}=0.0081$ \\
Variable & Coefficient & Std.error & t-stat & P-value \\
MPShock & -0.5252 & 0.2755 & -1.9063 & 0.0572 \\
Stocks(-1) & 0.0313 & 0.0460 & 0.6812 & 0.4961 \\
\hline Dep. Variable: & Net long & & & $R^{2}=0.5701$ \\
Variable & Coefficient & Std.error & t-stat & P-value \\
MPShock & -1049589 & 572459.9 & -1.8335 & 0.068769 \\
Netlong(-1) & 0.888 & 0.081 & 10.9428 & 0 \\
Netlong(-2) & -0.247 & 0.107 & -2.3145 & 0.022034 \\
Netlong(-3) & 0.188 & 0.081 & 2.3193 & 0.021767 \\
\hline \hline
\end{tabular}

policy shock appear to be non-significant. ${ }^{17}$ At any rate, we remark that coefficients are small, and the $R^{2}$ of the regression is also extremely tiny. ${ }^{18}$ Hence, the tentative conclusion could be that direct transmission channels are significant, but the bulk of the impact of monetary policy on commodity prices transits through the indirect channel of expected growth and inflation, as also reported by Barsky and Kilian (2004).

This being established, the next reasonable step is to assess the dynamic response of the variables to the monetary policy shock. We accomplish this in a VAR system, featuring the monetary policy shock and, in turn, oil supply, oil stocks and non-commercial net long positions. The preferred specification, according to the Akaike information criterion, is a $\operatorname{VAR}(1)$ for the case of production, a $\operatorname{VAR}(2)$ in the case of stocks and a $\operatorname{VAR}(3)$ for speculative positions.

The identification scheme adopted in these simple bivariate VARs is Choelski, with the monetary policy shock order first. ${ }^{19}$ Given the lack of significance of the lags of the monetary policy shock, as outlined above, impulse responses to a monetary policy shock (Figure 6) are not humpshaped, but rather smoothly-decreasing.

\footnotetext{
${ }^{17}$ We also tried different specifications including more lags of the dependent variable and/or the monetary policy shock, but we failed to identify any relevant pattern of significance. Therefore, to keep the model to a reasonable size, we decided to stick to a very parsimonious formulation, which is also preferred by any information criterion.

${ }^{18}$ The net speculative positions represent an exception with this respect, but we remark that most of the explanatory power of the regression come from the serial dependence of speculative positions on their past.

${ }^{19}$ This choice is motivated by the fact that in the regressions performed above we found a contemporaneous impact of the monetary policy shock on oil supply and inventories but not vice-versa.
} 
Figure 6: Impulse response functions to a 100 basis points monetary policy easing
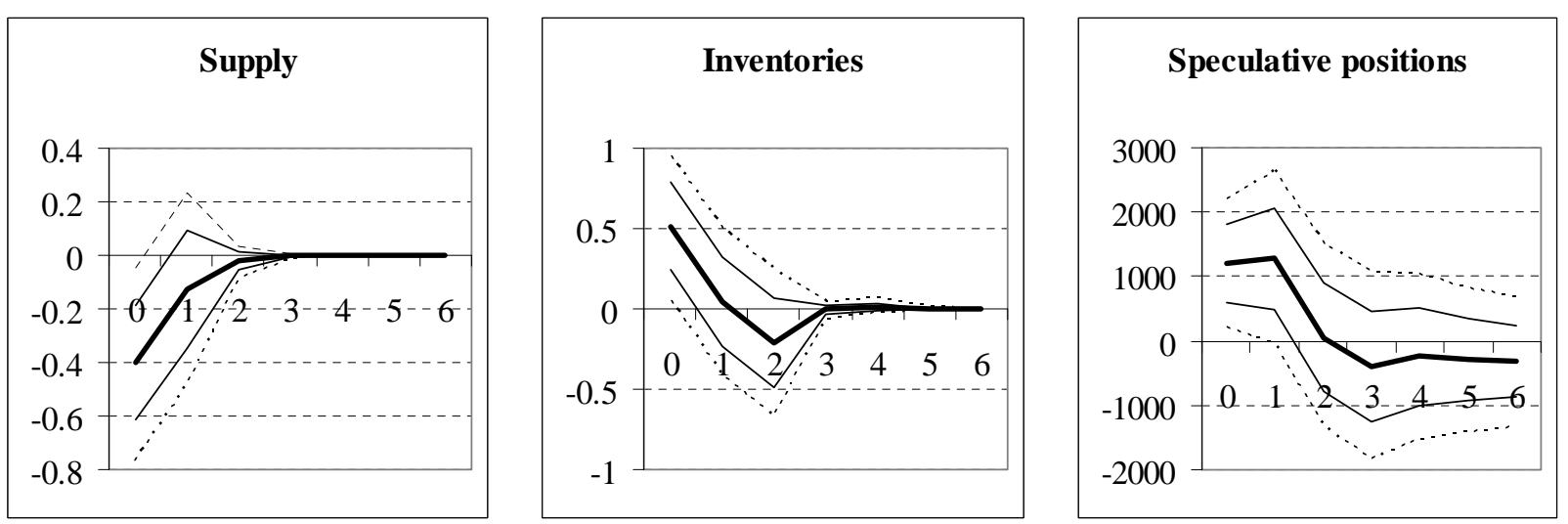

Notes: The x-axes report the months after the shock. Solid and dashed lines are, respectively, $68 \%$ and $90 \%$ confidence bands.

Having assessed that monetary policy plays a role in explaining - at least partly - oil price developments, and that the 'financial channel' appears to have some significance, an interesting question is whether the recent oil price surge and collapse can be ascribed to financial speculation. The issue, however, is very difficult to be examined for several reasons. First of all, the word 'speculation' has itself a plethora of nuances and a practical definition has to be agreed upon to make formal assessment. Furthermore, data limitations further hamper a thorough assessment.

Using, as a proxy for speculative activity, the net long positioning of non-commercial agents on the NYMEX disseminated by the CFTC, we test weather positions have some ability in predicting oil prices. Our results are based on a VAR system at weekly frequency from January 2, 1996 to November 2, 2009 (716 observations) featuring returns on WTI crude oil prices and non-commercial net long positions on WTI futures contracts. ${ }^{20}$ A Granger causality test (Table 2) highlights that the null hypothesis of absence of causality can be rejected only for what concerns the direction from prices to speculative positions. ${ }^{21}$ So, if any causality exists, it goes into the opposite direction: speculative positions do not cause price increases, but rather price increases can suggest speculators to enter the market and hence cause an increase in speculative positions.

Table 2: Granger causality test for speculative positions and returns on WTI oil prices

\begin{tabular}{ccc}
\hline \hline$H_{0}$ & F-stat & P-value \\
\hline NETLONG does not Granger Cause R_WTI & 0.68790 & 0.5030 \\
R_WTI does not Granger Cause NETLONG & 4.87384 & 0.0079 \\
\hline \hline
\end{tabular}

\footnotetext{
${ }^{20}$ This is due to the fact that CFTC discloses data on speculative positions at weekly frequency. Lag length in the VAR was chosen according to minimization of the Akaike Informaion Criterion.

${ }^{21}$ For the sake of robustness, we also repeated the test by including in the VAR crude oil stocks, and in that no causality relationship was found.
} 
Our results are in line with those already present in the literature, Gorton et al. (2008). Nevertheless, we also stress that this is the mostly wide indicator used in the literature (Haigh, Hranaiova and Overdahl, 2005, IMF, 2006). Using non-public CFTC data, Büyükşahin et al. (2008) conducted a wider set of test and found that the activity of non-commercial agents helped linking futures and spot prices; Haigh, Hranaiova and Overdahl (2007) fail to identify an impact of hedge funds on oil price volatility.

\subsection{Robustness check}

To check the robustness of our results on the transmission channel, we repeated the regression of Table 1 by employing different identification schemes for the monetary policy shock as explanatory variables. As in section 2.4, we have used a very simple Choleski scheme (Boivin and Giannoni, 2006), a financial-markets-based measure (Kuttner, 2001) and a more narrative approach (Romer and Romer, 2004).

Table 3: Regression results of oil supply, oil stocks on alternative monetary policy shocks

\begin{tabular}{cccc}
\hline \hline & Boivin \& Giannoni & Kuttner & Romer \& Romer \\
\hline Dep. Variable: Supply & & & \\
\hline MP Shock & $0.4908^{*}$ & -0.0017 & -0.0088 \\
MP Shock (-1) & - & $0.0109^{*}$ & - \\
Supply (-1) & $0.0363^{*}$ & -0.0995 & 0.0692 \\
Supply (-2) & $-0.1457^{*}$ & $-0.1444^{*}$ & $-0.1604^{*}$ \\
Supply (-3) & $-0.1223^{*}$ & - & - \\
\hline Dep. Variable: Stocks & & & \\
\hline MP Shock & $-0.5653^{*}$ & -0.0256 & -0.0019 \\
Stocks (-1) & - & - & 0.0273 \\
\hline Dep. Variable: Net long & & & - \\
\hline MP Shock & $-1242654^{\circ}$ & 25050.5 & - \\
Net long (-1) & $0.895^{* *}$ & $0.864^{* *}$ & - \\
Net long (-2) & $-0.276^{*}$ & $-0.157^{\circ}$ & - \\
Net long (-3) & $0.163^{*}$ & - & - \\
\hline \hline
\end{tabular}

$\circ{ }^{*}$ and ${ }^{* *}$ indicate, respectively, significance of the coefficientat the $10 \%, 5 \%$ and $1 \%$ level.

Results of the regressions are reported in Table 3; as before, the lag choice is motivated by the Schwarz information criterion. The shock à la Boivin and Giannoni (2006), being the one more closely related, in its construction, to Kim (1999), gives results that are very similar to those of Table 1, and thus confirms our analysis. For the other two shocks, the picture is a bit more blurred. Kuttner (2001) gives favourable results for the impact of the monetary policy shock on supply, but the impact on stocks, albeit of the correct sign, appears to be non-significant. The shock extracted 
using the Romer and Romer (2004) approach has instead always non-significant impacts, although the sign for stocks is correct. ${ }^{22}$

\section{Concluding remarks}

This paper constitutes a formal econometric assessment of the theoretical result, first presented by Frankel (1984), that monetary policy has an impact on commodity prices. Our main finding is supportive of this theoretical argument and in line with the results of Barsky and Kilian (2002) but we also found that the effect of an expansionary monetary policy in the US does not appear to be overwhelmingly large.

Our findings also suggest that the extraordinarily monetary policy easing deployed to contrast the real effects of the financial crisis is likely to push commodity prices up, albeit to a small extent. However, we acknowledge that our identification scheme is not designed to account for unconventional monetary policy measures, so that larger effects cannot be ruled out. While this is of course an interesting research avenue, it would require a brand new identification strategy for the monetary policy shock which is beyond the scope of this paper.

\footnotetext{
${ }^{22}$ Due to limited data availability, we could not check the impact of the Romer and Romer (2004) shock on net long positions in futures markets.
} 


\section{Appendix}

Figure 7: Impulse response functions to a 100 basis points monetary policy easing under alternativve identifications
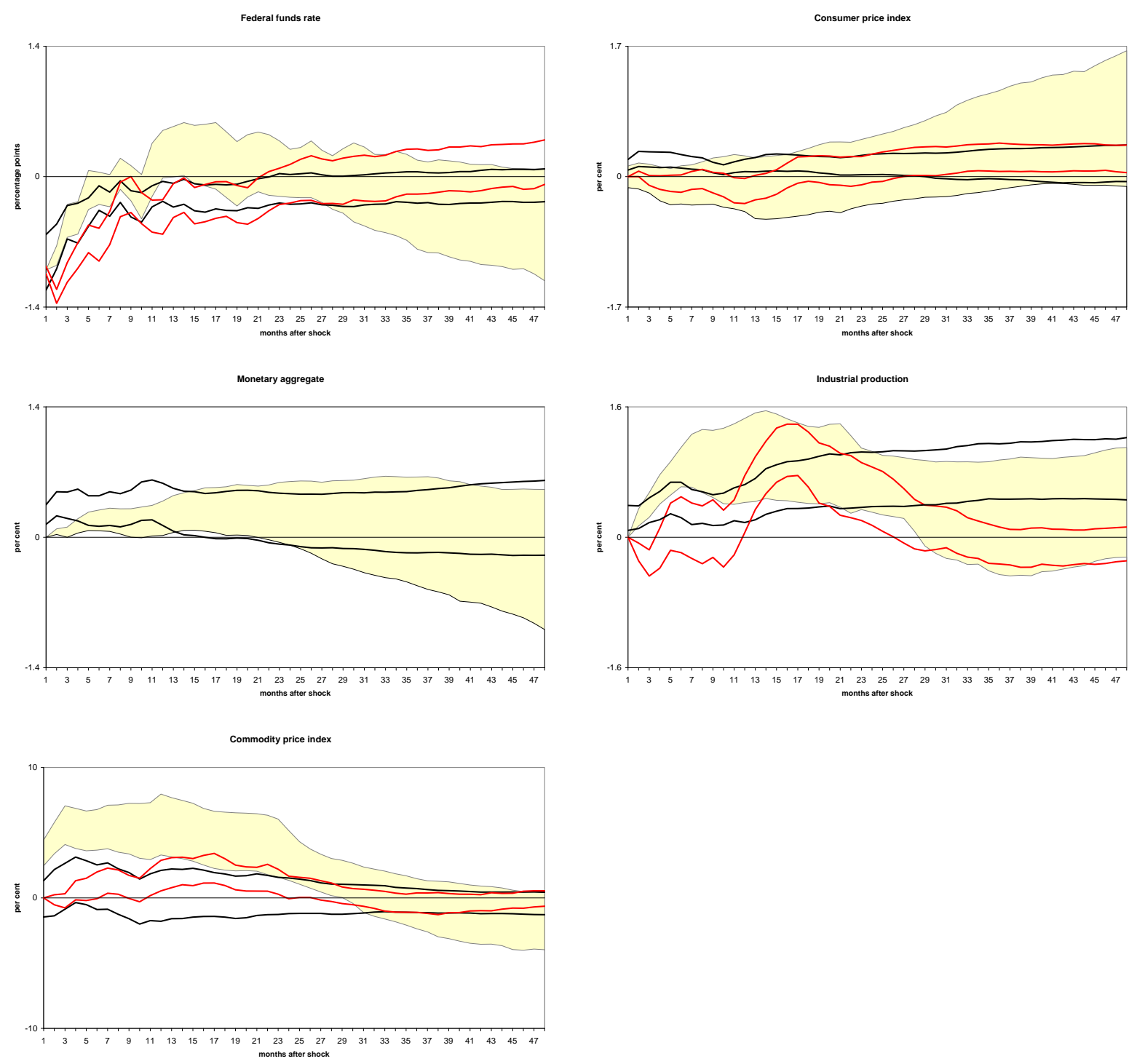

Notes: the x-axes reports the months after the shock; $68 \%$ confidence bands. shaded areas reproduce the bands under the baseline identification; red lines = Boivin and Giannoni (1986); black lines = sign restrictions. 


\section{References}

[1] Alquist, R. and L. Kilian (2010), "What do we learn from the price of crude oil futures?", Journal of Applied Econometrics, forthcoming.

[2] Anzuini, A., P. Pagano and M. Pisani (2007), "Oil supply news in a VAR: Information from financial markets", Temi di discussione No. 632, Banca d'Italia.

[3] Barsky, R.B. and L. Kilian (2002) "Do we really know that oil caused great stagflation? A monetary alternative", NBER Macroeconomics Annual 16: 137-198.

[4] Barsky, R.B. and L. Kilian (2004) "Oil and the macroeconomy since the 1970s", Journal of Economic Perspectives 18: 115-134.

[5] Bernanke, B.S., M. Gertler, Mark, and M.W. Watson (1997), "Systematic monetary policy and the effects of oil price shocks", Brookings Papers on Economic Activity 1: 91-142.

[6] Boivin, J. and M.P. Giannoni (2006), "Has monetary policy become more effective?", Review of Economics and Statistics 88: 445-462.

[7] Büyükşahin, B., Haigh, M.S., Harris, J.H., Overdahl, J.A. and M.A. Robe (2008), "Fundamentals, trader activity and derivative pricing", EFA 2009 Bergen Meetings Paper.

[8] Canova, F. and De Nicolò, G. (2002), "Monetary Disturbances Matter for Business Fluctuations in the G-7", Journal of Monetary Economics, 49 (6): 1121-59.

[9] Christiano, L.J., M. Eichenbaum and C.L. Evans (1999). "Monetary policy shocks: what have we learned and to what end?" In: Taylor, J., Woodford, M. (Eds.), Handbook of Macroeconomics, vol. $1 \mathrm{~A}$.

[10] Faust, J. (1998). "The Robustness of Identified Var Conclusions About Money", CarnegieRochester Conference Series on Public Policy, 48: 207-44.

[11] Faust, J., E. T. Swanson and J. H. Wright (2004). "Identifying VARS Based on High Frequency Futures Data", Journal of Monetary Economics, vol. 51: 1107-1131.

[12] Frankel, J.A. (1984), "Commodity prices and money: lessons from international finance", American Journal of Agricultural Economics 66: 560-566.

[13] Frankel, J.A. (1986), "Commodity expectations and commodity price dynamics: the overshooting model", American Journal of Agricultural Economics 68: 344-348.

[14] Frankel, J.A. (2007), "The effect of monetary policy on real commodity prices", in "Asset prices and monetary policy", edited by J. Campbell, University of Chicago press.

[15] Frankel, J.A. and G.K. Hardouvelis (1985), "Commodity prices, money surprises, and Fed credibility", Journal of Money, Credit and Banking 17: 427-438. 
[16] Frankel, J.A. and A.K. Rose (2009), "Determinants of agricultural and mineral commodity prices", unpublished working paper.

[17] Fry, R. and Pagan, A. (2007). "Some Issues in Using Sign Restrictions for Identifying Structural Vars" (National Centre for Econometric Research Working Paper 14, April 2007).

[18] Furlong, F. and R. Ingenito (1996). "Commodity prices and inflation," Economic Review, Federal Reserve Bank of San Francisco: 27-47

[19] Gillman, M. and A.A. Nakov (2008), "Monetary effects on oil and gold prices", Cardiff Economics Working Papers E2008/15, Cardiff University.

[20] Gorton, G.B., F. Hayashi and K.G. Rouwenhorst (2008), "The Fundamentals of Commodity Futures returns", NBER Working Paper 13249.

[21] Haigh, M.S., J. Hranaiova and J.A. Overdahl (2005), "Price dynamics, price discovery and large futures trader interactions in the energy complex", CFTC Working paper.

[22] Haigh, M.S., Hranaiova, J. and J.A. Overdahl (2007), "Price volatility, liquidity provision, and the role of hedge funds in energy futures markets," Journal of Alternative Investments: Spring 2007.

[23] Hamilton, J.D. (2009), "Understanding crude oil prices", Energy Journal 30: 179-206.

[24] International Monetary Fund (2006), "The boom in nonfuel commodity prices - Can it last?", World Economic Outlook, Chapter 5: September 2006.

[25] Kilian, L. (2008), "The economic effects of energy price shocks", Journal of Economic Literature 46: 871-909.

[26] Kilian, L. and C. Vega (2008), "Do energy prices respond to U.S. macroeconomic news? A test of the hypothesis of predetermined energy prices", CEPR Discussion Papers 7015.

[27] Kilian, L. (2009), "Not all oil price shocks are alike: Disentangling demand and supply shocks in the crude oil market", American Economic Review 99: 1053-1069.

[28] Kilian, L and L. Lewis (2009), "Does the Fed respond to oil price shocks?", CEPR Discussion Papers 7594.

[29] Kim, S. (1999), "Do monetary shocks matter in the G-7 countries? Using common identifying assumptions about monetary policy across countries", Journal of International Economics 48: $387-175$.

[30] Kim, S. (2001), "International transmission of US monetary policy shocks: Evidence from VARs", Journal of Monetary Economics 48: 339-372.

[31] Kuttner, K.N. (2001), "Monetary policy surprises and interest rates: Evidence from the Fed funds futures markets", Journal of Monetary Economics 47: 523-544. 
[32] Nakov, A.A. and A.Pescatori (2010), "Oil and the Great Moderation", Economic Journal, forthcoming.

[33] Pagano, P. and M. Pisani (2009), "Risk-adjusted forecasts of oil prices", The B.E. Journal of Macroeconomics, vol. 9, iss.1.

[34] Romer, C.D. and D.H. Romer (2004), "A new measure of monetary shocks: Derivation and implications", American Economic Review 94: 1055-1084.

[35] Rubio-Ramírez, J. F., D.Waggoner and T. Zha (2010), "Structural vector autoregressions: theory of identification and algorithms for inference", Review of Economic Studies, 77: 665-96

[36] Svensson, L. E. O. (2005), "Oil prices and ECB Monetary Policy", manuscript, www.princeton.edu/ svensson/papers/ep501.pdf.

[37] Uhlig, H. (2005), "What are the Effects of Monetary Policy on Output? Results from an Agnostic Identification Procedure", Journal of Monetary Economics, 52 (2): 381-419. 
